\title{
General dental practice and improved oral health: is there a win-win for both the professional establishment and government?
}

\author{
Wayne Richards, ${ }^{* 1}$ Teresa Filipponi² and Anne-Marie Coll²
}

\section{Key points}

This paper provides a novel approach to monitoring oral health outcomes in general dental practice.
The approach has the potential to impact on social inequalities in oral health.
The approach allows general practitioners, who wish to deliver services to impact on community oral health to do so without the burden of current disincentives.

\begin{abstract}
General dental practice in the United Kingdom has been in a state of unrest for over two decades, with practitioners having been confronted by two contract changes. The latest contract change of 2006 resulted in much disquiet, and services continue to be piloted in order to develop a contract that satisfies the needs of both government and the profession. Within this context, this paper explores the issues surrounding the present situation. To date, the profession has expanded service provision into the private market which has resulted in an exaggerated inverse care provision. This could be perceived as a move towards a retail philosophy and away from healthcare. In order to restore an equitable balance of care provision, the authors present possible solutions that could satisfy both parties.
\end{abstract}

\section{Background}

There is currently a blame game between professional associations and the government regarding oral health in the United Kingdom (UK). This is demonstrated clearly in Wales where the British Dental Association (BDA) published a paper demonstrating problematic access to dental care for lower socio-economic groups. ${ }^{1}$ The solution to this tension from the viewpoint of the $\mathrm{BDA}$ is increased resources, whereas the Welsh Government is not in agreement for increases. ${ }^{2,3}$ The BDA view this as a missed opportunity to improve oral health. This paper aims to rationalise the situation from an objective viewpoint and presents the authors' understanding of the problem. The authors also present a potential solution to overcome the present position.

1Professor, Community General Dental Practice, University of South Wales, Faculty of Life Sciences and Education Glyntaff, Pontypridd, CF37 4BD, UK; ${ }^{2}$ Senior Lecturer, University of South Wales, Faculty of Life Sciences and Education, Glyntaff, Pontypridd, CF37 4BD, UK;

${ }^{\star}$ Correspondence to: Wayne Richards

Email address: wayne.richards@southwales.ac.uk

Refereed Paper.

Accepted 12 February 2020

https://doi.org/10.1038/s41415-020-1448-3
Figure 1 suggests a model as to how the population, government and professional establishments interact in democratic society. The population elect its government and pay taxes according to the rules made by the elected government. The government, in turn, administers the services provided by the professional establishments within the population. The government decides whether services should be delivered under subsidised conditions or unsubsidised conditions. Subsidised services will be delivered under the constraints of the rules of the subsidy, whereas unsubsidised services will be delivered under market forces. The government will decide whether a service should be supported according to the fundamental values and philosophies of the elected government. The

\section{Fig. 1 Balance between population, government and professional establishment}

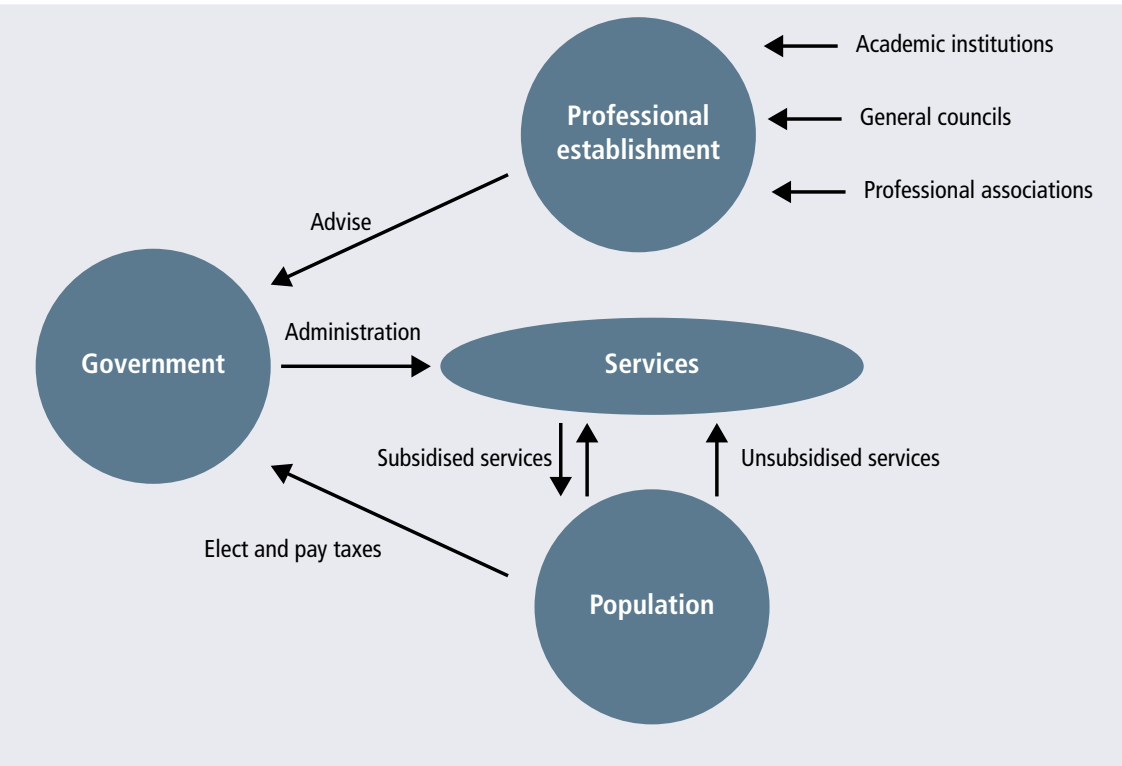


government will not have the specialised knowledge base of the professional establishment and therefore will take guidance from the professional establishment with regards to the delivery of the service. The professional establishment will be influenced by research generated by academic institutions, general councils and professional associations.

Within the UK, the National Health Service (NHS) is a service which has been valued by successive governments with different values and philosophies. As a health service, dental services have been included within the NHS. As a subsidised service, General Dental Practitioners (GDPs) have worked within the rules and regulations of the service. Since the inception of the NHS, oral health has improved significantly within UK populations in the twenty-first century experiencing different levels of dental decay. ${ }^{4,5}$ As a result, the rules and regulations of service delivery have evolved accordingly. A milestone change occurred in 2006 when a new dental contract in England and Wales was facilitated through a government vote to change the law to enable administrators to manage the financial contracts delivered by GDPs. ${ }^{6}$ The contract was designed to allow GDPs to change their operating practices to service the changed needs within the community, following the epidemiological improvements in oral health. ${ }^{7}$ The distribution of disease in the population is described in the next section of this paper in order to explain dental need in the community.

Current epidemiological surveys show that over half the population of the UK at the age of five years has not experienced dental decay. The Welsh Government published its Delivery Plan - Together for Health: A National Oral Health Plan for Wales 2013-18, which states: 'The most common oral disease of childhood is dental caries (tooth decay). Children living in deprived communities in Wales have the poorest dental health in the United Kingdom (UK). Tooth decay is found in all population groups but it is more common in deprived communities. While many five year old children across Wales have no decayed teeth, over $40 \%$ experience a high disease burden and have, on average, four teeth decayed, filled or extracted. ${ }^{8}$ However, the latest epidemiological surveys have shown that only $34 \%$ of five-yearolds experience dental decay. Of the $34 \%$, not all experience the same magnitude of disease. Half of the $34 \%$ that experience dental decay will have less teeth affected than the other half. The other half will have significantly more

Fig. 2 Distribution of disease in the community (grey = caries free, green = minimal caries, red $=$ multiple caries)

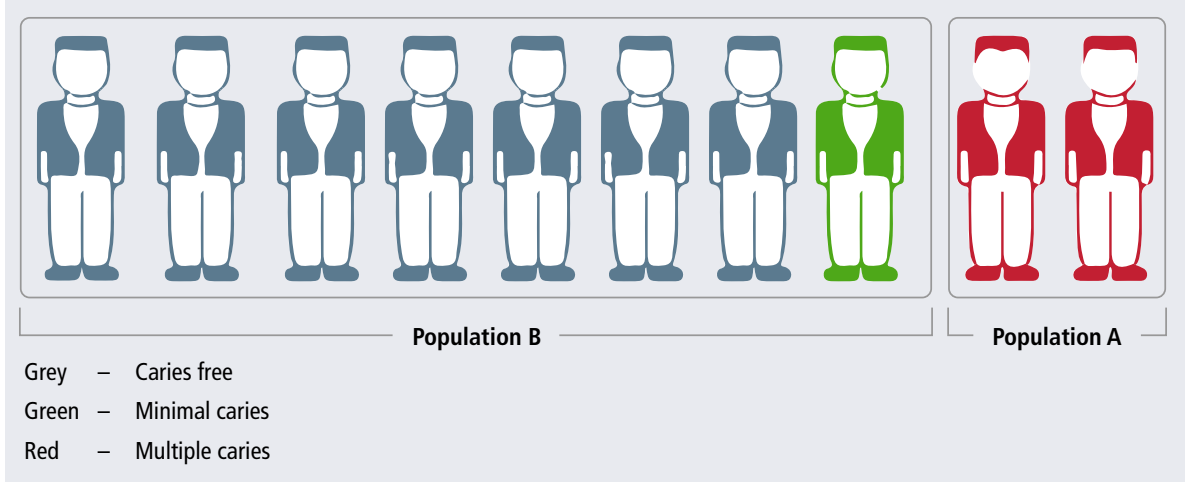

teeth affected and this distribution will differ in different unitary authorities depending on the deprivation profile of the unitary authority. ${ }^{9}$ Dental professionals describe the 80:20 distribution of dental decay in the population, which means that $80 \%$ of the disease is found in $20 \%$ of the population. ${ }^{10}$ Simply, we have two populations; the first (Fig. 2, population B) has no or low disease experience; the second (Fig. 2, population A) has high disease experience and behaviours that create disease activity in the oral cavity. ${ }^{11}$ The improvement in caries trends are observed in diverse populations. ${ }^{12,13}$ Baelum (2010) suggests that this decline has also trickled into the adult population. ${ }^{14}$

The 2006 contract was based on the need to reform general dental practice in the context of improved community oral health. Service change was to be facilitated by contract management which was transferred to the administrators, Primary Care Organisations (PCOs), who now had the power to lever services in the direction of population need. This enabled the administrators to identify the distribution of disease in the community and address social inequalities observed. ${ }^{15}$ To date, administrators have failed to influence service delivery for several reasons, ${ }^{16}$ the main reason being the contract of 2006 as discussed hereby.

The contract of 2006 allocated Units of Dental Activity (UDAs) to the activities of GDPs. One UDA for an examination, three UDAs for a course of routine treatment regardless of the number of fillings needed, and 12 UDAs for advanced treatments involving laboratory work. Contract values were based on historic performance figures for each practitioner, where the number of examinations were allocated one UDA each, the number of routine courses of treatment were allocated three UDAs each, and the number of advanced courses of treatment were allocated 12 UDAs each. The GDP was then monitored in the first and subsequent years on the number of units generated based on historic figures. This generated an unintended consequence where individual GDPs realised that patients with a high need (population A) required more treatment per UDA and therefore generated fewer UDAs per unit of time than healthier patients with low need (population B). Suddenly, the administrators began to use what is termed 'gaming and splitting, ${ }^{17}$ where GDPs were accused of using the system inappropriately in order to achieve their UDA targets. Gaming related to cherry-picking patients and splitting related to completing courses of treatment prematurely before the patient was made dentally fit.

The reaction of the professional establishment to this was to guide the administrators to further qualify the definitions of each category of treatment. The administrators were now addressing the timing of treatment delivered, so that a patient who attended for a filling between courses of treatment generated an urgent treatment claim of only 1.2 UDAs. Richards (2009), while chairing the review of Dental Services in Wales, recognised that this would compound inequalities in oral health in an editorial published in the British Dental Journal (BDJ). ${ }^{18}$

PCOs (Local Health Boards in Wales) had a duty to provide emergency care for patients requiring immediate access to dental services (mainly but not exclusively, Population A) and to set up systems to provide such care. This service does not facilitate ongoing continuing care for patients. Service documentation assumes that irregular symptomatic attenders make a choice for irregular symptomatic care, with no reference to methods for converting irregular attenders to become regular attenders. ${ }^{19,20}$ 
While the remit of the administrators was and is to manage NHS dental contracts, many of the GDPs holding the contracts also operate(d) unsubsidised private dental care within the same organisation, making capacity management problematic. It has been reported that the number of contract holders who are also delivering NHS treatments across Wales have halved between 2010 and 2018 , from 418 to $155 .{ }^{1}$

In Wales, following the review of dental services, pilot contracts have been managed and delivered. ${ }^{21}$ The number of pilot contracts have been expanded from 23 in January 2018 to 95 in April 2019. These contracts are based on the delivery of treatments and process control. To quote ABMU's response to the Welsh Government's Health Social Care and Sport Committee: 'The ABMU pre-2017 legacy is that, from 2011 onwards the two Prototype practices had their standard Unit of Dental Activity [UDA] target removed from their contract and were instead paid on a Capitation and Quality Payment which focused on patient numbers and promoting prevention. Recording of activity on a UDA basis continued as a background check.'22

Monitoring consists of treatment provision and process control defined as 'quality measures'. Preventive treatments include the provision of hands-on fluoride varnishes. There is little outcome measurement of the effectiveness of behavioural interactions with dental teams in terms of addressing inequalities in oral health and practice capacity in meaningful ways. There is no consideration within these sites on the contribution of unsubsidised (private) care provided by the organisations.

\section{Literature}

Taylor-Gooby et al. (2000) following an earlier contract change in the 1990s studied the professional values held by dentists in an attempt to rationalise the expansion of private dentistry following the change. ${ }^{23}$ The study reported that dentists valued a restorative paradigm as opposed to a preventive paradigm which devalues traditional restorative skills. The authors suggested that altruistic motives lead in the direction of good quality restorative care.

Holden (2013) used a philosophical framework to discuss the relevance of justice in the provision of NHS dental care and asked whether the 2006 contract fostered a focus on targets rather than improving oral health. ${ }^{24}$

Lloyd-Godwin et al. (2019) discussed how and why capitation affects GDP behaviour

Fig. 3 a) Deprivation profile of Wales and two Welsh unitary authorities. b) Deprivation profile of unitary authority and a dental practice within the authority. c) Deprivation profile of unitary authority and three dental practices within the authorities

$$
\text { Deprived Not deprived }
$$

A) Deprivation profile of Wales and two Welsh Unitary Authorities

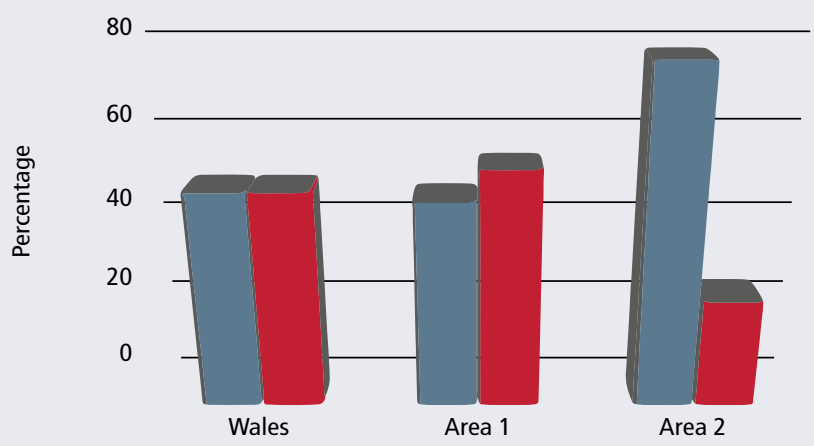

B) Deprivation profile of Unitary Authority and a dental practice within the authority

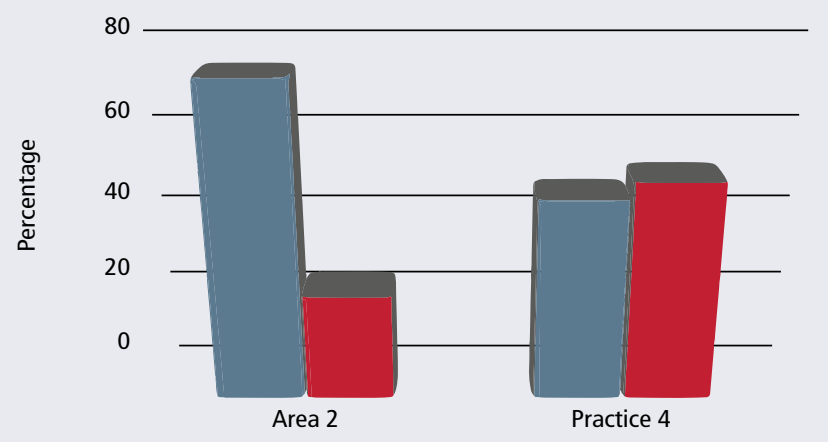

C) Deprivation profile of Unitary Authority and three dental practices within the authorities

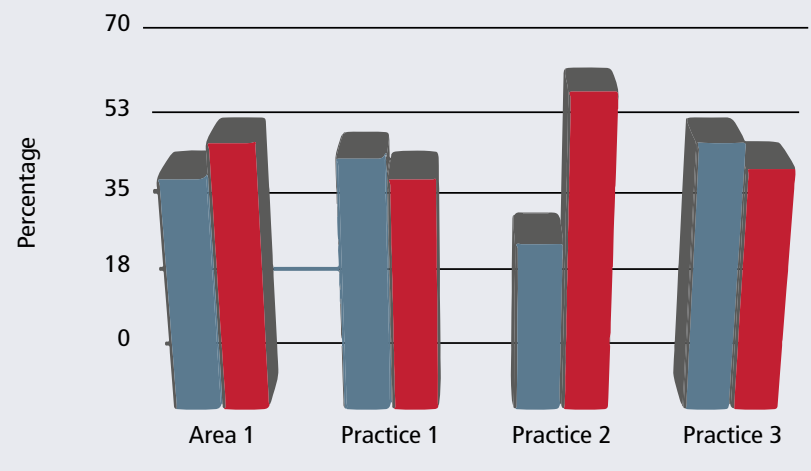

and concluded that; for some, capitation may change behaviour in the direction of prevention; for others, it will disincentivise certain treatments; while for others, it will make no change in their clinical practice. ${ }^{25}$

A model of care called 'Community General Dental Practice' focused on outcomes that were not based on treatment numbers but rather organisational profiles. Practice profiles were considered to be fundamental to monitoring activity. ${ }^{26}$ Practice profiles show the number of patients seen within a two-year period, which provides a snapshot of capacity within the practice. In order to qualify capacity, the socio-demographic profile of the patients seen can be identified from postcodes and observed. This is important if an impact is to be made on the population sub-group with the greatest need. ${ }^{27}$ PCOs need to be mindful of the fact that a practice situated in a deprived location may not necessarily service the surrounding area. This was demonstrated in the published audit undertaken in 2006 of eight GDPs in four locations (Fig. 3). It can be seen that area 1 is marginally not deprived than deprived, whereas area 2 is significantly more deprived 
than not. However, practice 4 servicing area 2 has more non-deprived patients than deprived, even though it is a deprived area. Moreover, in area 1, two practices (1 and 3) show a practice deprivation profile that demonstrates they are servicing more than their share of the deprived population. The responsibility for administrators to consider this fact was also published in a letter in the BDJ. ${ }^{28}$

While there is much in the literature using postcodes to demonstrate inequalities in oral health, such as Jones et al. (2013) $)^{29}$ and Landes and Jardine (2010), ${ }^{30}$ there is little on individual practice sites. ${ }^{31}$ As stated in the Department of Health's 'Improving oral health with the new dental contract,', it can be seen that administrators are key to improving oral health in communities. While the NICE guidelines on recall for routine dental examinations have been published for many years, ${ }^{33}$ since the application of the 2006 contract, little concern has been shown by PCOs regarding the monitoring of this guideline and the impact it has on capacity.

\section{Potential solution}

To enable solutions in oral health inequalities, the authors suggest that dentists consider changing the altruistic mindset from valuing treatments and process control towards the objective monitoring of population oral health, which should also include good quality treatments. This can be achieved through measuring:

- Deprivation profile of the practice

- Capacity - cost per person registered (seen within last two years)

- Retention - ratio of numbers of patients who return regularly for care:

o Whole practice (>10 years, 5-9 years, 2-4 years, $<2$ years)

o Most deprived category (>10 years, 5-9 years, 2-4 years, $<2$ years).

The potential for a practice to retain its patients can be achieved if the above ratios are measured. Following measurement, rationalisation can be undertaken. Comparing the ratio of the whole practice with that of the deprived sub-group can show if retention ratios are the same for the whole practice and the difficult-to-get deprived group. Currently, the system does not facilitate ongoing care for those patients attending for emergency/urgent care; therefore, it would be expected that the deprived category (Population A, Fig. 2) would show poor retention ratios.

This type of monitoring could certainly be a feature of the pilot sites. Once data are available, comparisons can then be made within and between sites. This will show which of the site(s) is/are servicing deprived populations and retaining those from the most deprived areas. This demonstrates effective prevention where it is needed rather than caring for the worried well. Furthermore, training packages can be developed to help those practices that are weak at delivering prevention to become more effective.

\section{Discussion}

While the above data are not currently collected, ${ }^{34}$ it would not impact on the workload of the individual clinicians as the data only need to be extracted from systems that currently exist. ${ }^{35}$ Dental practitioners have been trained to be responsible for delivering appropriate care to their patients and currently the General Dental Council has shown an active role in monitoring this in conjunction with the legal establishment. ${ }^{36}$

It is clear that not every GDP will want to practise under a subsidised NHS service to improve oral health in the community. However, there will be some GDPs who would want to improve community oral health, yet currently the system of remuneration disincentivises these practitioners due to the constrains placed on them by the administrators.

Administrators within PCOs function under the direction of government. The government relies on dental professional advisors for direction. Administrators, as non-professionals, can only take advice from government and their Local Dental Committees. It seems that all the advice has been focused on valuing treatments and process control when observing current actions. Indeed, Neville and Waylen (2019) ask why UK dental education should take a greater interest in the behavioural and social sciences (BeSS). They state: 'To ensure the development of these professional skills the BeSS should be fully integrated into the UK dental curriculum and not just offered as an "add-on" to the undergraduate programme.37 This provides the opportunity to improve the delivery of effective prevention, which could impact on deprivation profiles of practices and capacity.
Much of the services delivered by GDPs are not based in health and should not be made available under subsidised care. Such services include tooth whitening or facial aesthetics. The division between subsidised care (subsidy paid by the tax payer) and unsubsidised care is a grey area which could be monitored through profile monitoring. Some GDPs will service a population with a demand for services that are not within the remit of subsidised care and they should be allowed to deliver the services as individual treatments or care contracts. Shadrav et al. (2019), looking at dental services in the United States and Spain, accept the fact that the population using dental services has been static since the recession. The demand for dental services has declined while the supply of dentists has risen; this generates a need to retain those using services in order to secure practice viability in a competitive market. ${ }^{38}$ The authors in the above suggest marketing methods to retain service users as do retail organisations.

Contemporary concepts of good quality care/treatment are quite different today, and these should be reflected in patient care and practice profiles. Take, for example, the practice of minimally invasive treatment; Chana et al. (2019) highlight that a practitioner's restorative threshold and choice of treatment is negatively affected by the number of years since qualification and positively influenced by attending a caries management course. ${ }^{39}$ The application of contemporary concepts of good dentistry will increase competition within the competitive market place identified by Shadrav et al. ${ }^{38}$

\section{Concluding remarks}

Whether dental services are perceived by society as healthcare or retail is a question that can only be answered through surveying populations. From observations of dental practice advertisements and availability and accessibility of services in the UK, we fear the weight is on the latter. Actions speak louder than words; therefore, much needs to be done to address availability and accessibility of services to redress the balance towards healthcare. An NHS service that impacted on an 'untapped population A' market could satisfy the needs of both the profession and the government. This reality can only be achieved through appropriate funding streams to reward behaviours that generate objective measurable health outcomes. These funding streams are under the control of PCOs. 


\section{References}

1. Owen C, Seddon C, Clarke K, Bysouth T. NHS genera dentistry Wales: evaluation of patient access and budget expenditure Br Dent J 2019: 226: 967-977.

2. National Assembly for Wales: Health, Social Care and Sport Committee. A Fresh Start: Inquiry into dentistry in Wales. 2019. Available at https://www.assembly. wales/laid\%20documents/cr-ld12528/cr-ld12528-e.pdf (accessed March 2020).

3. BDA Wales. BDA Analysis of Welsh Government Responses to the Assembly Inquiry to Dentistry Report and Recent AM Questions on Access to Dentistry. 2019.

4. Downer M C. Time trends in caries experience of children in England and Wales. Caries Res 1992; 26: 282-285.

5. Downer M. Models of financing dental services. A review. Community Dent Health 2005; 22: 188-189.

6. UK Government. National Health Service Act 2006. Available at https://www.legislation.gov.uk/ ukpga/2006/41/contents (accessed March 2020).

7. Richards W, Toy A. Improving Oral Health with the New Dental Contract. Br Dent J 2007: 203: 453-455.

8. Welsh Government. Delivery Plan - Together for Health: A National Oral Health Plan for Wales 2013-18. 2013. Available online at https://www.wales.nhs.uk document/214894 (accessed March 2020).

9. Public Health Wales. Picture of Oral Health 2017 Dental caries in 5-year-olds (2015-2016) Update. 2017.

10. Tickle M. The 80:20 phenomenon: help or hindrance to planning caries prevention programmes? Community Dent Health 2002; 19: 39-42.

11. Richards W. Does the Genera Dental Practitioner have a role in tackling oral health inequalities? Prim Dent J 2013; 2: 58-63.

12. Marthaler T M, O'Mullane D M. The prevalence of dental caries in Europe 1990-1995. Caries Res 1996; 30: 237-255.

13. Petersen P E. The World Oral Health Report 2003: Continuous improvement of oral health in the 21st century - the approach of the WHO Global Oral Health Programme. 2003. Available online at https://www. who.int/oral_health/media/en/orh_report03_en.pdf (accessed March 2020).

14. Baelum V. What is an appropriate caries diagnosis? Acta Odontol Scand 2010; 68: 65-79.
15. Richards W, Gear T. Changes in the Balance Between Dentists, Patients and Funders in the NHS and their Consequences. Prim Dent Care 2008; 15: 13-16.

16. Laverty L, Harris R. Can conditional health policies be justified? A policy analysis of the new NHS dental contract reforms. Soc Sci Med 2018; 207: 46-54.

17. GDPUK. Dentist struck off for 'gaming'. 2013. Available at https://www.gdpuk.com/news/latest-news/1335dentist-struck-off-for-gaming (accessed March 2020).

18. Richards W. Moving Goal Posts. Br Dent J 2009; 206: 237.

19. NHS Wales. Welsh Dental Pilot Programme - End of Pilot Report. 2015.

20. Miller Research. Final Evaluation of Welsh Dental Contracts report to Welsh Government. 2015.

21. Welsh Government. Taking Oral Health Improvement and Dental Services Forward in Wales. 2017. Available at https://gov.wales/sites/default/files/ publications/2019-04/taking-oral-health-improvementand-dental-services-forward-in-wales.pdf (accessed March 2020).

22. NHS Wales. Abertawe Bro Morgannwg University Health Board [ABMU] response to the Health, Social Care and Sport Committee's inquiry into dentistry in Wales. 2018. Available at http://senedd.assembly.wales/documents/ s78701/Paper $\% 204 \% 20$ - 20 Abertawe $\% 20$ Bro $\% 20$ Morgannwg\%20University\%20Health\%20Board.pdf (accessed March 2020)

23. Taylor-Gooby P, Sylvestor S, Calnan M, Manley G. Knights, knaves and gnashes: professional values and private dentistry. J Soc Pol 2000; 29: 375-395.

24. Holden A C L. Justice and NHS dental treatment - is injustice rife in NHS dentistry? Br Dent J 2013; 214: 335-337.

25. Lloyd-Godwin T, Brocklehurst P, Hall B, McDonald R, Tickle M, Williams L. How and why does capitation affect general dental practitioner' behaviour? A rapid realist review. Br J Health Care Manage 2018; 24: 505-513.

26. Richards W, Ameen J R M, Coll A M. The community general dental practitioner. $\mathrm{Br} J$ Health Care Manage 2005; 11: 309-312.

27. Richards W, Ameen J, Higgs $G$. Adapting to change: dental prescriptions. Br J Health Care Manage 2008; 14: 500-504.
28. Richards W, Higgs G. Redeploying Resources. Br Dent J 2010; 209: 328

29. Jones C M, Clouting D, McCarthy G. Socio-economic status of patients registered with NHS dental services in Scotland: an inverse 'dental' care law? Br Dent J 2013; DOI: 10.1038/sj.bdj.2013.223.

30. Landes D P, Jardine C. Targeting dental resources to reduce inequalities in oral health in the North East of England - a health equity audit methodology to evaluate the effects of practice location, practice population and deprivation. Br Dent J 2010; DOI: 10.1038/ sj.bdj.2010.676.

31. Richards W. Oral ill-health and deprivation among patients of a general dental practice in South Wales. Prim Dent Care 2002; 9: 105-112.

32. Department of Health. Improving oral health with the new dental contract. CD-ROM. 2007.

33. NICE. Dental checks: intervals between oral health reviews - Clinical guideline [CG19]. 2004. Available online at https://www.nice.org.uk/guidance/cg19 (accessed March 2020)

34. Personal communication with Welsh Government. 8 April 2019

35. NHS Digital. Supplementary information - statistics produced by request. Available online at https://digital. nhs.uk/data-and-information (accessed March 2020).

36. NHS Business Services Authority. Prescription data. Available at https://www.nhsbsa.nhs.uk/prescriptiondata (accessed March 2020).

37. General Dental Council. Standards and guidance. Available at https://www.gdc-uk.org/informationstandards-guidance/standards-and-guidance (accessed March 2020).

38. Neville P, Waylen A. Why UK dental education should take a greater interest in the behavioural and social sciences. Br Dent J 2019; 227: 667-670.

39. Shadrav A, Kalenderian E, Roig P. "7/12" patient touch point strategy: a novel method to increase patient attendance and recommendation. BDJ Open 2019; DOI: 10.1038/s41405-019-0023-y.

40. Chana P, Orlans M C, O'Toole S, Domejean S, Movahed $S$, Banerjee A. Restorative intervention thresholds and treatment decisions of general dental practitioners in London. Br Dent J 2019: 227: 727-732. 